INTERNATIONAL

FOOD POLICY

RESEARCH

INSTITUTE

IFPRI

IFPRI Discussion Paper 01870

September 2019

Weather Dataset Choice Introduces Uncertainty to Estimates of Crop Yield Responses to Climate Variability and Change

Ben Parkes

Thomas P. Higginbottom

Koen Hufkens

Francisco Ceballos

Berber Kramer

Timothy Foster

Markets, Trade, and Institutions Division South Asia Regional Office 


\section{INTERNATIONAL FOOD POLICY RESEARCH INSTITUTE}

The International Food Policy Research Institute (IFPRI), established in 1975, provides research-based policy solutions to sustainably reduce poverty and end hunger and malnutrition. IFPRI's strategic research aims to foster a climate-resilient and sustainable food supply; promote healthy diets and nutrition for all; build inclusive and efficient markets, trade systems, and food industries; transform agricultural and rural economies; and strengthen institutions and governance. Gender is integrated in all the Institute's work. Partnerships, communications, capacity strengthening, and data and knowledge management are essential components to translate IFPRI's research from action to impact. The Institute's regional and country programs play a critical role in responding to demand for food policy research and in delivering holistic support for country-led development. IFPRI collaborates with partners around the world.

\section{AUTHORS}

Ben Parkes (ben.parkes@manchester.ac.uk) School of Mechanical, Aerospace and Civil Engineering, University of Manchester, Manchester, UK.

Thomas P. Higginbottom, School of Mechanical, Aerospace and Civil Engineering, University of Manchester, Manchester, UK.

Koen Hufkens (koen.hufkens@gmail.com), Computational \& Applied Vegetation Ecology Lab, Faculty of Bioscience Engineering, Ghent University, Ghent, Belgium.

Francisco Ceballos (f.ceballos@cgiar.org) is an Associate Research Fellow in the Markets, Trade, and Institutions Division of the International Food Policy Research Institute (IFPRI), Washington, DC.

Berber Kramer (b.kramer@cgiar.org), is a Research Fellow in the Markets, Trade, and Institutions Division of the International Food Policy Research Institute (IFPRI), Washington, DC.

Timothy Foster (timothy.foster@manchester.ac.uk), School of Mechanical, Aerospace and Civil Engineering, University of Manchester, Manchester, UK.

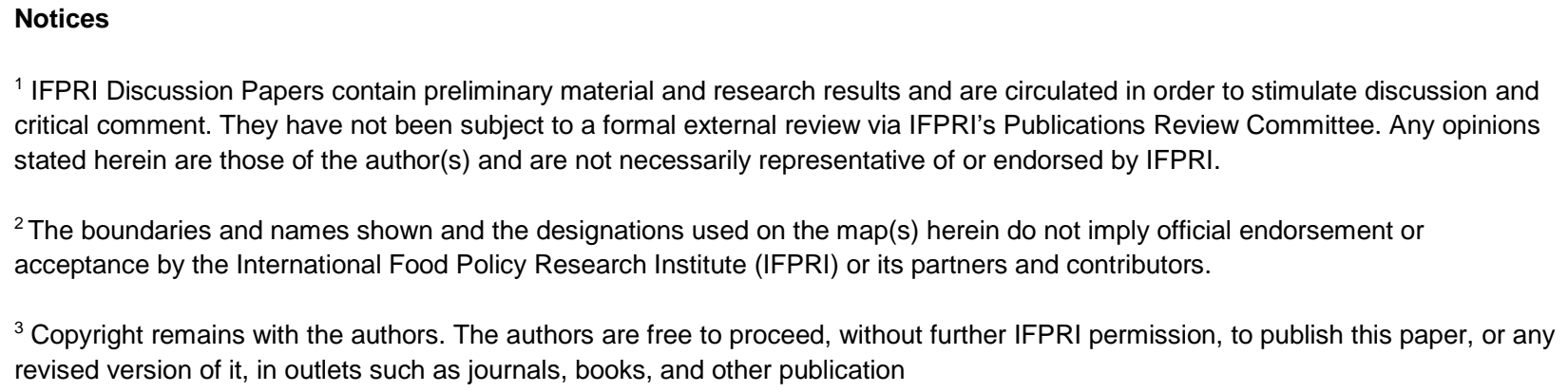




\title{
Weather dataset choice introduces uncertainty to estimates of crop yield responses to climate variability and change
}

\author{
B. Parkes ${ }^{1}$, T. P. Higginbottom ${ }^{1}$, K. Hufkens ${ }^{3}$, F. Ceballos $^{2}$, B. \\ Kramer ${ }^{2}$, T. Foster ${ }^{1}$, \\ ${ }^{1}$ Department of Mechanical, Aerospace and Civil Engineering, University of Manchester, \\ Oxford Road, Manchester, M13 9PL, UK \\ ${ }^{2}$ International Food Policy Research Institute, 1201 Eye St, NW, Washington, DC 20005-3915 \\ USA \\ ${ }^{3}$ Computational \& Applied Vegetation Ecology Lab, Faculty of Bioscience Engineering, Ghent \\ University, Coupure Links 653, Ghent 9000, Belgium \\ E-mail: ben.parkes@manchester.ac.uk
}

\begin{abstract}
.
Extreme weather events, such as heatwaves, droughts, and excess rainfall, are a major cause of crop yield losses and food insecurity worldwide. Statistical or process-based crop models can be used to quantify how yields will respond to extreme weather and future climate change. However, the accuracy of weather-yield relationships derived from crop models, whether statistical or process-based, is dependent on the quality of the underlying input data used to run these models. In this context, a major challenge in many developing countries is the lack of accessible and reliable meteorological datasets. Gridded weather datasets, derived from combinations of insitu gauges, remote sensing, and climate models, provide a solution to fill this gap, and have been widely used to evaluate climate impacts on agriculture in data-scarce regions worldwide. However, these reference datasets are also known to contain important biases and uncertainties. To date, there has been little research to assess how the choice of reference datasets influences projected sensitivity of crop yields to weather. We compare multiple freely available gridded datasets that provide daily weather data over the Indian sub-continent over the period 19832005 , and explore their implications for estimates of yield responses to weather variability for key crops grown in the region (wheat and rice). Our results show that individual gridded weather datasets vary in their representation of historic spatial and temporal temperature and precipitation patterns across India. We show that these differences create large uncertainties in estimated crop yield responses and exposure to extreme weather events, which highlight the need for improved consideration of input data uncertainty in statistical studies that explore impacts of climate variability and change on agriculture.
\end{abstract}

\section{Introduction}

Farmer livelihoods depend strongly on weather conditions during the growing season. Smallholder subsistence farmers in developing countries in Africa and Asia, in particular, are impacted disproportionately by extreme weather events due to their lower adaptive 
capacity and dependence on agriculture for basic staple crop production, nutrition and incomes. In this context, understanding crop yield responses in smallholder farming systems to different types and magnitudes of weather shocks is critical for predicting impacts of future climate variability and change on agricultural productivity and food security, and for designing appropriate strategies to reduce exposure to weather-related production risks.

To assess the impacts of weather and future climate on agriculture, crop models are commonly used to simulate yield responses to different meteorological conditions. Two types of modelling approaches exist. Statistical yield models (e.g. Lobell and Burke (2010); Cai et al. (2014); Duncan et al. (2015, 2016); Parkes et al. (2017, 2018)) develop empirical relationships between observed weather conditions and crop yields reported through field surveys or agricultural censuses. In contrast, process-based models, such as APSIM (Holzworth et al.; 2014) or AquaCrop (Foster et al.; 2017), use mathematical representations of plant physiology to simulate crop growth and yield development for specified meteorological conditions, soil properties, and management practices. Both modelling approaches have strengths and weaknesses (Roberts et al.; 2017). Importantly, where sufficient observed yield data exist, statistical models may provide additional information about yield sensitivity to climate due to their ability to account for the effects of unobserved farmer management practices or indirect weatherrelated drivers of yield losses that cannot be simulated by process-based models (e.g. mechanical damage by hail or wind, pests, diseases, etc) (Roberts et al.; 2017).

In many regions worldwide, and in particular in developing countries where agriculture underpins food security and rural livelihoods, there is a lack of reliable and comprehensive historical weather records from in situ monitoring stations. Consequently, statistical models typically are developed using weather data drawn from national, regional, or global gridded weather datasets. A diverse range of gridded weather datasets exist (e.g. Funk et al. (2015); Ashouri et al. (2015); Ruane et al. (2015); Yatagai et al. (2012)), each differing in the underlying source of primary observations (e.g. satellite data, model reanalysis, etc), the variables reported (e.g. temperature, precipitation, solar radiation, etc), and the resolution (spatial and temporal) at which these data are reported. Differences in the data sources and algorithms used to create these gridded products mean that reported meteorological conditions at a given location and time can often vary substantially across datasets. For example, the high resolution of $0.05^{\circ}$ used in the Climate Hazards Group InfraRed Precipitation with Station (CHIRPS) (Funk et al.; 2015) is able to resolve storms a few kilometres across which are blurred out by the coarser resolution datasets such as the $0.75^{\circ}$ ECMWF Re-Analysis Interim (ERA-Interim) (Dee et al.; 2011).

Despite these known differences, the choice of weather dataset is often an arbitrary decision in studies that use these datasets to evaluate climate impacts on agriculture and other sectors (Auffhammer et al.; 2012; Cai et al. 2014; Duncan et al.; 2016). To date, there has been little evaluation of how the choice of reference weather datasets affects estimates of implied sensitivity of agriculture to climate variability and change 
from statistical crop yield models. In this study, we address this knowledge gap by developing multiple statistical crop yield models for wheat and rice production in India using 50 unique reference weather dataset combinations. Our study focuses on India due to the availability of comprehensive historical yield observation data, along with the widespread past use of statistical modelling approaches in India and South Asia as part of climate impact research (Asseng et al.; 2017; Duncan et al.; 2015, 2016; Gilmont et al.; 2018; Jain et al.; 2017; Lobell et al.; 2012; Mondal et al.; 2016). Our findings show that weather dataset choice has little impact on the overall predictive power of statistical crop yield models, but introduces significant uncertainty in the magnitude of yield responses to specific weather extremes. We demonstrate that failure to account for these differences can lead to large biases in predicted impacts of future climate change on agriculture, and also has important implications for robust assessment and mitigation of farmers' exposure to weather-related production risks.

\section{Methods}

\subsection{Study area}

Crop yield observations required to train statistical crop yield models are obtained from a panel dataset of district-level yield observations for rice and wheat from across India provided by the ICRISAT VDSA (Village Dynamics in South Asia) study database (http://vdsa.icrisat.ac.in/vdsa-database.aspx). For this study, we use yield data for the period 1983-2005 to align with the common temporal coverage period for available gridded weather products (Table 1), and omit district-year observations where reported cropped area of wheat or rice was less than 1000 acres in any year of our record. These restrictions retain 267 districts for wheat and 299 districts for rice. Districts for each crop are geographically spread across most of India, omitting mostly the extreme northern districts where terrain is mountainous, along with a small number of districts in eastern India, where administrative boundary changes make identifying consistent locations infeasible.

\subsection{Weather datasets}

To develop statistical models of weather impacts on wheat and rice yields, we use a total of 50 different reference gridded weather dataset combinations (precipitation and temperature) that are available for the Indian subcontinent. Table 11 summarises the key features of these datasets (name, resolution, variables, data sources, and key references). As we observe yields only at the district level, and as almost all districts in India are significantly larger than the resolution of available gridded weather products, temperature and precipitation variables for each year are calculated as the area-weighted average of variable totals across all pixels that fall within a given district boundary before development of statistical models of weather-yield relationships.

Of the gridded weather datasets included in our analyses (Table 1), four (some 
reporting both temperature and precipitation) rely on satellite data as a primary source of weather observations - AgMERRA, PERSIANN-CDR, NASA POWER, and CHIRPS. In contrast, two datasets use weather station data as their primary source of information for generating gridded weather observations - the APHRODITE, and Indian Meteorological Department (IMD) datasets. The final four datasets use weather model reanalysis as their data source: ERA-Interim, Princeton, and two variants of the WATCH-Forcing-Data-ERA-Interim (WFDEI-CRU and WFDEI-GPCC) that are differentiated based on the reference precipitation dataset used to generate the product. The sources here are not necessary the only source used and datasets such as CHIRPS use a blend of satellite and station data that is subsequently bias corrected. See S1 and S2 for examples of the differences between the datasets.

Many of the weather datasets reported in Table 1 have been used in past studies of climate impacts on agriculture in India and more broadly in South Asia. For example, precipitation - only datasets (i.e. CHIRPS, APHRODITE, PERSIANN-CDR, IMD) have been used to analyse impacts of drought and rainfall extremes on agricultural yields and water demands in the region (DeFries et al.; 2016; Romaguera et al.; 2010; Aadhar and Mishra; 2017). Similarly, the Princeton and ERA-Interim datasets have been used in assessing regional droughts (Mishra et al.; 2014) and water resource assessments (Mathison et al.; 2013), while WFDEI has been used as an input in a study on irrigation demand (Biemans et al. 2016). AgMERRA has been used to analyse the uncertainty of aggregating crop yields from large scale studies (Porwollik et al.; 2017). Finally, NASA POWER has been widely applied for modelling temperature - related impacts on wheat yields in the South Asia region (Asseng et al.; 2017). Although not an exhaustive list, these studies highlight both the regional relevance of the datasets and their history of use in agricultural and climate impacts research across the Indian sub-continent.

\subsection{Yield models}

We develop a total of 50 unique statistical crop yield models for both rice and wheat in India, using the different combinations of available gridded temperature and precipitation datasets described in Table 1 and Section 2.2. Following Lobell and Burke (2010), wheat yield models are formulated as linear regressions relating observed crop yields to growing season aggregates of precipitation and temperature (growing degree days and extreme degree days). The rice yield model uses a similar specification to the wheat yield models, but omits the extreme degree day term to maintain consistency with prior statistical models of rice yields in South Asia Auffhammer et al.; 2012; Fishman; 2016). Specifically, the wheat and rice yield models are defined as follows:

$$
\begin{aligned}
& \text { Wheat }: \ln \left(Y_{t, i}\right)=a_{i}+b G D D_{t, i}+c E D D_{t, i}+d P_{t, i}+f_{s}(t)+\epsilon_{t, i} \\
& \text { Rice }: \ln \left(Y_{t, i}\right)=a_{i}+b G D D_{t, i}+d P_{t, i}+f_{s}(t)+\epsilon_{t, i}
\end{aligned}
$$

where: $Y_{t, i}$ is the crop yield from district $i$ in year $t, a_{i}$ is a district-specific fixed effects term (i.e. district-level intercept) to account for unobserved time-invariant drivers of 
yield differences between districts, $G D D_{t, i}$ is the total seasonal growing degree days, $E D D_{t, i}$ is the total seasonal extreme degree days (EDD), $P_{t, i}$ is the total seasonal precipitation, $b, c$ and $d$ are model parameters, $f_{s}(t)$ is a state-specific quadratic time-trend representing growth in yields through breeding and other improvements to management practices, and $\epsilon_{t, i}$ is the error term. The natural log of yield is taken to produce models that provide relative changes instead of absolute changes, since this moderates the effects of districts having significantly different absolute yields.

Precipitation, growing degree days (GDD) and extreme degree days per season are calculated as the sum of the daily values of these variables within the respective growing seasons for wheat (November to February) and rice (June to September) (Auffhammer et al.; 2012; Datta and Jong; 2002). Daily values of GDD and EDD are calculated as shown in Equations 3 and 4 below, accounting for the within-day distribution of temperatures by fitting a sinusoidal curve between observed maximum and minimum temperatures on each day following the approach proposed by Schlenker and Roberts (2009). This approach to GDD and EDD estimation is selected as it is provides a more robust estimate of daily degree day accumulation compared to using a simple daily average temperature, which does not account for within-day temperature distributions and thus may affect statistical model performance (Roberts et al.; 2017; Fontes et al.; 2017).

$$
\begin{aligned}
& G D D=\int_{T_{\text {base }}}^{\infty} \min \left(T-T_{\text {base }}, T_{\text {upp }}-T_{\text {base }}\right) \phi(T) \\
& E D D=\int_{T_{s t r}}^{\infty}\left(T-T_{s t r}\right) \phi(T)
\end{aligned}
$$

where $T$ is the temperature, $\phi(T)$ is the daily cumulative distribution of interpolated temperatures based on the sinusoidal fit between the daily maximum and minimum temperatures, and $T_{\text {base }}$ and $T_{u p p}$ are crop-specific lower and upper temperature limits, respectively, for GDD accumulation. For wheat, these lower and upper limits are equal to $0^{\circ} \mathrm{C}$ and $30^{\circ} \mathrm{C}$ (Lobell et al.; 2012). In contrast, for rice, limits of $8^{\circ} \mathrm{C}$ and $30^{\circ} \mathrm{C}$ are chosen following van Oort et al. (2011). EDD accumulation occurs for temperatures above a threshold temperature limit for the initiation of heat stress $\left(T_{\text {str }}\right)$, which we set

equal to $30^{\circ} \mathrm{C}$ for wheat consistent with prior econometric yield models (Schlenker and Roberts; 2009; Roberts et al.; 2017; Tack et al.; 2015). As described earlier, no value is specified for rice as EDDs are omitted from these models.

\subsection{Assessing uncertainty in future crop yield change}

A common use of statistical crop yields models is to predict how agricultural production will respond to future changes in climate conditional on existing management practices and technologies being hold constant (Lobell and Burke; 2010). In this study, we explore the effect of the choice of the reference weather training dataset on the predicted impacts of climate change on Indian agriculture by applying a range of idealized future temperature and precipitation change scenarios to our set of 50 unique statistical wheat 
and rice yield models. Temperature change scenarios in our analysis involved perturbing baseline daily temperature values by between $-2^{\circ} \mathrm{C}$ and $+2^{\circ} \mathrm{C}$ in increments of $1^{\circ} \mathrm{C}$ in each reference dataset. Updated seasonal GDD and EDD totals in each district and year are then calculated using these perturbed daily temperature time series holding threshold limits for GDD/EDD accumulation constant consistent with assumptions of no changes in crop varietal properties in this analysis. Precipitation change scenarios in turn were constructed by modifying existing seasonal precipitation totals for each dataset, district and year by between $-20 \%$ and $+20 \%$ in steps of $10 \%$. We apply each combination of perturbed precipitation and temperature (GDD and EDD) totals as inputs to statistical yield models generated in Section 2.3 to generate projections of future yield changes, and, in particular, evaluate uncertainty in yield change projections resulting from the choice of historical reference weather dataset.

\section{Results}

Our results show that only limited differences are observed in the overall predictive power of models based on the underlying choice of reference weather dataset. Based on a test for the joint significance of estimated coefficients, all models are highly significant $(p<0.001)$ and can capture a large proportion of the observed spatial and temporal variability in district-level wheat $\left(R^{2}>0.85\right)$ and rice $\left(R^{2}>0.80\right)$ yields. However, the choice of reference weather dataset does lead to large differences in the significance and magnitude of individual estimated weather coefficients. From this, several key insights can be drawn to inform the use of such models in weather and climate impact assessment (Figures 1 and 2).

\section{Weather dataset choice alters implied crop yield sensitivity to climate}

While all models perform equally well in explaining overall yield variability, Figures 1 and 2 highlight that only limited consensus exists across models about the magnitude and significance of crop yield sensitivity to specific meteorological variables and extreme events. For wheat, GDDs are a significant $(p<0.05)$ and positive predictor of crop yields (i.e. yields increase with GDDs) for all datasets, in agreement with previous studies of wheat production in South Asia (Mondal et al.; 2016). Increasing EDDs has a negative impact on wheat yields for all datasets. However, the negative impact of EDD's is only statistically significant $(p<0.05)$ for two datasets based on the temperature thresholds and specifications adopted in this analysis, highlighting that weather dataset choice can have important implications for robustness of conclusions drawn about climatic driver of yield variability. A clear difference in temperature coefficients - both for GDD and EDD - is also observed for models using NASA POWER temperature data, for which coefficient sizes are noticeably smaller than other temperature datasets (Figure 1). This can be explained by the hot bias in POWER temperature data relative to other datasets (Figure S1), resulting in higher EDD totals and therefore a smaller coefficient. 
POWER's hot temperature bias also has the effect of blurring the identification of positive GDD and negative EDD effects, as the temperature threshold for wheat is assumed to be crop rather than dataset specific. Figure S1 demonstrates this effect, showing that more than $65 \%$ of daily observations during the wheat growing season have a higher maximum temperature than $30^{\circ} \mathrm{C}$ - the lower limit for EDD accumulation - for POWER. By contrast, ERA-Interim has the smallest percentage of days (14\%) that exceed $30^{\circ} \mathrm{C}$ during the wheat growing season. We suggest that this may explain the greater significance and larger coefficient size for EDD in wheat models using ERA-Interim temperature data, which captures a much smaller subset of true extreme temperature events in comparison with other datasets.

In general higher precipitation has a positive effect on wheat yields for all datasets except WFDEI-CRU. However, for the majority of datasets, precipitation is not a significant predictor $(p>0.05)$ of wheat yields, reflecting the fact that wheat is commonly irrigated across much of India. Indeed, it is noticeable that for many datasets the identification of precipitation as a predictor of yield variability is not robust, with significance changing substantially depending on the choice of paired temperature dataset. CHIRPS is the only dataset for which precipitation has a consistently significant relationship with wheat yields. CHIRPS predicts a stronger effect than any of the other precipitation datasets, perhaps reflecting the greater capacity of CHIRPS to capture aggregated impacts of sub-district rainfall heterogeneity. However, it is important to note that the absolute differences in the size of precipitation coefficients are small across datasets (Figure S3). Yield differences for each additional $10 \mathrm{~mm}$ of total seasonal precipitation ranging from $14.2 \mathrm{~kg} /$ ha for CHIRPS to $-2.2 \mathrm{~kg} / \mathrm{ha}$ for WFDEI-GPCC. $14.2 \mathrm{~kg} / \mathrm{ha}$ is less than $1 \%$ of the average wheat yield in the dataset, despite a change in average seasonal precipitation of between 15 and $30 \%$ relative to baseline conditions (Figure S2).

For rice, precipitation is a consistently positive and significant predictor of variability in crop yields over space and time in India (Figure 2), reflecting the fact that rice is predominantly grown under rainfed or partial irrigation conditions (DeFries et al. 2016). However, variations in the size of the precipitation coefficients exist between datasets, with coefficient values ranging from $1.66 \times 10^{-4}$ to $3.90 \times 10^{-4} \ln (\mathrm{kg} / \mathrm{ha}) / \mathrm{mm}$. These values mean that an increase in seasonal rainfall of $100 \mathrm{~mm}$ would result in a yield increase of between $31.4 \mathrm{~kg} / \mathrm{ha}$ and $62.2 \mathrm{~kg} / \mathrm{ha}$, a non-trivial level of uncertainty as total monsoon (kharif) seasonal precipitation (averaged across all years and datasets) in India is $869 \mathrm{~mm}$. For all datasets, GDDs are found to have a negative impact on rice yields. This finding indicates that higher temperatures lead to yield reductions, and is consistent with previous econometric studies of rice yields in India Auffhammer et al.; 2012; Fishman; 2016). However, as with precipitation, notable heterogeneity exists across datasets, with yield reductions per 100 GDDs ranging from $56.3 \mathrm{~kg} / \mathrm{ha}$ for Princeton to $177.1 \mathrm{~kg} /$ ha when using ERA-Interim.

The models in this study are based on seasonal totals for precipitation, GDDs and EDDs instead of the sub-seasonal totals used with most process-based models. Crop 
yields are known to be affected by intraseasonal timing (Dalhaus et al.; 2018; Hufkens et al.; 2019) and intensity (Fishman; 2016) of extreme weather events. Incorporating sub-seasonal weather variables is likely to exacerbate differences between models even further as individual gridded weather datasets are known to differ substantially in their ability to capture intraseasonal weather dynamics, for example the size and arrival of the South Asian monsoon (Ceglar et al.; 2017).

\section{Predicted impacts of climate change vary with reference dataset choice}

The changes in predicted wheat yields for each model under potential climate change scenarios are shown in Figure 3 . The range in yield changes for a one degree increase in temperature is between $-0.45 \pm 0.07 \%$ when using models trained on IMD temperature data, and $-1.15 \pm 0.01 \%$ when using models trained on ERA-Interim temperature data (where the uncertainty is the standard deviation across the precipitation datasets for a given temperature dataset). For a two degree increase in temperature, yield changes for wheat expand further to $-1.13 \pm 0.18 \%$ (IMD dataset) and $-2.97 \pm 0.03 \%$ (ERA-Interim dataset). These two results highlight how the low temperature bias in ERA-Interim affects the yield-temperature relationship for projected crop yields. The increase in temperature leads to an increase in EDDs, which in turn reduce the yield. Effects of precipitation changes on yields are smaller in magnitude, with the changes in yields for a $20 \%$ increase in seasonal precipitation ranging from $-0.10 \pm 0.04 \%$ (WFDEI-GPCC dataset) to $0.59 \pm 0.28 \%$ (CHIRPS dataset) reflecting the smaller effects of precipitation on wheat yields in India.

Results of the climate scenario analyses for rice are shown in Figure 4 . Rice results show a significantly larger disagreement in future yield changes between datasets, reflecting greater heterogeneity in coefficient sizes for baseline rice models as shown in Figure 2. For example, a 20\% increase in seasonal precipitation for rice leads to an increase in yields of between $3.47 \pm 0.26 \%$ (IMD dataset) and $6.67 \pm 0.53 \%$ (AgMERRA dataset). In contrast, a two degree increase in temperature results in rice yield reductions of anywhere between $3.50 \pm 0.76 \%$ (Princeton dataset) and $7.51 \pm 0.98 \%$ (ERA-Interim dataset) when holding precipitation constant at historical levels. Notably, there is large uncertainty in the combined effects of uncertain future changes in temperature and

precipitation. For example, yield changes for a one degree temperature increase and a $10 \%$ precipitation increase range from $2.46 \%$ for the POWER temperature + POWER precipitation model to $6.32 \%$ for POWER temperature + ERA-Interim precipitation model - a spread of over $3 \%$ based on reference dataset choice alone.

\section{Discussion and Implications}

Understanding the meteorological drivers of crop yield variability is important for assessing exposure of agriculture to climate risks, and for designing effective strategies to mitigate impacts of future climate change. For a case study in India, our findings 
highlight that our understanding of the sensitivity of crop yields to climate variability and change is affected strongly by the choice of reference weather dataset used to train baseline statistical models. Variations between different reference weather datasets result in large uncertainty in understanding of current weather-yield relationships, and, in turn, for subsequent predictions of future climate-induced changes in agricultural productivity and food security (Van Wart et al.; 2013).

In order to address these challenges, there is an urgent need for greater evidence about the ability of different gridded data products to capture spatial and temporal weather variability in major agricultural regions. Research focused on comparing and evaluating gridded weather datasets to date has been predominantly based on in-situ observations from monitoring networks in North America and Europe (Behnke et al.; 2016; Beck et al.; 2017; Mourtzinis et al.; 2017), with fewer studies in smallholder farming environments in Africa and Asia due to the more limited availability, coverage, and reliability of weather station data records in these locations (Menne et al.; 2012; Van Wart et al.; 2015; Heft-Neal et al.; 2017). In these regions, our findings suggest that modellers therefore should be cautious in using only a single gridded weather data product to understand current and future agricultural climate risks. Specifically, we recommend that multiple gridded weather datasets should instead be used when developing statistical crop yield models in absence of information about the most reliable gridded weather dataset, an approach that is comparable to the use of multi-model ensembles in climate and other geophysical modelling studies (Tebaldi and Knutti; 2007; Rosenzweig et al.; 2014).

Alongside these recommendations, our findings also highlight the importance of weather datasets consistency throughout the design and application of statistical weather-yield models. As an illustrative example, Figure 5 shows the errors in estimated average wheat and rice yields when a statistical model is trained on POWER temperature and CHIRPS precipitation dataset and then used to predict yields using alternative combinations of different input precipitation and temperature datasets (see Figure S4 and S5 for results using all dataset combinations). Importantly, such errors may have significant implications for several end uses of statistical crop yield models. For example, weather index insurance policies, which are widely offered to smallholder farmers in India and other regions as a way to help mitigate financial risks posed by weather-related crop losses (Barnett and Mahul; 2007; Clarke et al.; 2012), are often designed and implemented using a range of different weather data sources (e.g. longterm gridded weather data for regional contract design versus short-term station data for triggering localised payouts). Each of these may contain a different underlying bias. Where differences in biases are large, the performance of index insurance products may be negatively affected due to an over-estimation or under-estimation of underlying climate risks for farmers. This insight is comparable with previous conclusions about the robustness of weather index insurance under non-stationary climate, which highlight that insurance performance deteriorates as weather conditions deviate from historical benchmarks due to factors such as multi-decadal climate variability and man-made 
climate change (Daron and Stainforth; 2014).

Finally, while the discussion thus far in this paper has focused on the impacts of gridded weather dataset differences in the context of statistical crop yield modelling, it is important to note that dataset bias will also pose similar challenges when using biophysical process-based crop models. Process-based crop models internally specify fixed biological relationships between growing season weather conditions and crop yields. For example, the APSIM model assumes that terminal heat stress for wheat is initiated for temperatures above $34^{\circ} \mathrm{C}$. Any biases in input weather datasets therefore will alter process-based model predictions of expected yield variability, which, in turn, may result in either an over- or under-estimation of weather-related production risks in a given farming system. Using an input weather dataset with a hot temperature bias (e.g. POWER) will, all else being equal, lead a process-based crop model to predict greater frequencies and magnitudes of yield losses due to extreme heat than if the same simulations were run using an input temperature dataset without such a bias. As with statistical crop yield modelling, in the absence of objective information about the accuracy of different gridded weather datasets, we argue that addressing this challenge requires greater use of ensembles of gridded weather datasets in process-based crop model simulations. Such an approach would provide a more accurate picture of the uncertainty in estimates of the exposure of agriculture to climate risks, and, in turn, improve the robustness of policy and management recommendations about how to improve resilience of smallholder farming to extreme weather and climate change.

\section{Acknowledgements}

This work was supported by funding from NERC-ESRC-DFID grant NE/R0104094/01; the CGIAR Research Programs on Climate Change, Agriculture and Food Security (CCAFS) and on Policies, Institutions, and Markets (PIM) led by the International Food Policy Research Institute (IFPRI); and the CGIAR Platform for Big Data in Agriculture. Dr Parkes is the recipient of the Ekpe Research Impact Fellowship in the Department of Mechanical, Aerospace and Civil Engineering at The University of Manchester. 
Table 1. Name, abbreviation, resolution, indication of temperature or precipitation data, time frame, primary type of source data and key reference for the reference datasets. Where $\mathrm{T}$ and $\mathrm{P}$ indicate if the dataset provides temperature or precipitation data respectively. Datasets that list "Present" as their end time can be delayed by a few months. See S6 for a visual representation of the differences in resolution.

\begin{tabular}{|c|c|c|c|c|c|c|c|}
\hline Name & Abbrev. & Res. & $\mathrm{T}$ & $\mathrm{P}$ & Time frame & Primary source type & Reference \\
\hline AgMERRA & $\mathrm{Ag}$ & $0.25^{\circ}$ & $\mathbf{X}$ & $\mathbf{X}$ & $1980-2010$ & Satellite record & Ruane et al. (2015) \\
\hline APHRODITE & $\mathrm{AP}$ & $0.50^{\circ}$ & & $\mathbf{X}$ & $1951-2007$ & Weather station data & Yatagai et al. $(2012)$ \\
\hline CHIRPS & $\mathrm{CH}$ & $0.05^{\circ}$ & & $\mathbf{X}$ & 1981 - Present & Bias corrected satellite record & Funk et al. (2015) \\
\hline ERA-Interim & $\mathrm{ER}$ & $0.75^{\circ}$ & $\mathbf{X}$ & $\mathbf{X}$ & 1979 - Present & Reanalysis & Dee et al. (2011). \\
\hline IMD-Precipitation & IM & $0.50^{\circ}$ & & $\mathbf{X}$ & $1969-2005$ & Weather station data & Pai et al. (2014); Rajeevan and Bhate (2009) \\
\hline IMD-Temperature & IM & $1.00^{\circ}$ & $\mathbf{X}$ & & $1969-2005$ & Weather station data & Pai et al. (2014); Rajeevan and Bhate $(2009$ \\
\hline PERSIANN-CDR & $\mathrm{PE}$ & $0.25^{\circ}$ & & $\mathbf{X}$ & 1983 - Present & Satellite record & Ashouri et al. (2015) \\
\hline POWER & $\mathrm{PO}$ & $0.50^{\circ}$ & $\mathbf{X}$ & $\mathbf{X}$ & 1981 - Present & Satellite record & Stackhouse et al. $(2018)$ \\
\hline Princeton & $\operatorname{Pr}$ & $0.25^{\circ}$ & $\mathbf{X}$ & $\mathbf{X}$ & $1948-2016$ & Reanalysis & Sheffield et al. $(2006)$ \\
\hline WFDEI-CRU & $\mathrm{WC}$ & $0.50^{\circ}$ & & $\mathbf{X}$ & $1979-2016$ & Bias corrected reanalysis & Weedon et al. (2014); Harris et al. (2013) \\
\hline WFDEI-GPCC & WG & $0.50^{\circ}$ & & $\mathbf{X}$ & $1979-2016$ & Bias corrected reanalysis & 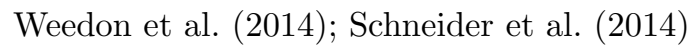 \\
\hline
\end{tabular}



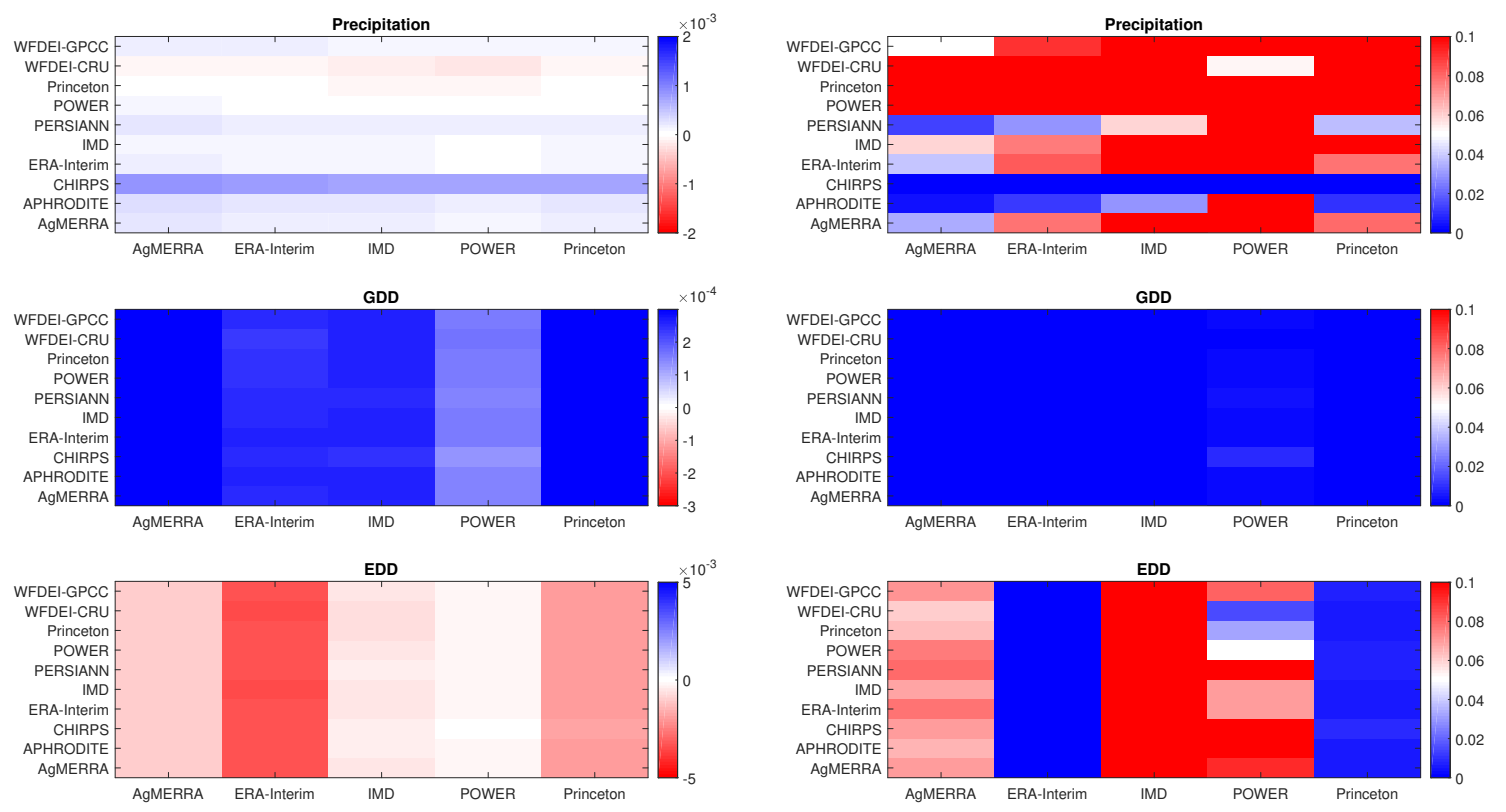

Figure 1. Coefficients (left) and significance values (right) for variables from fixed effects panel regression models for Wheat. 

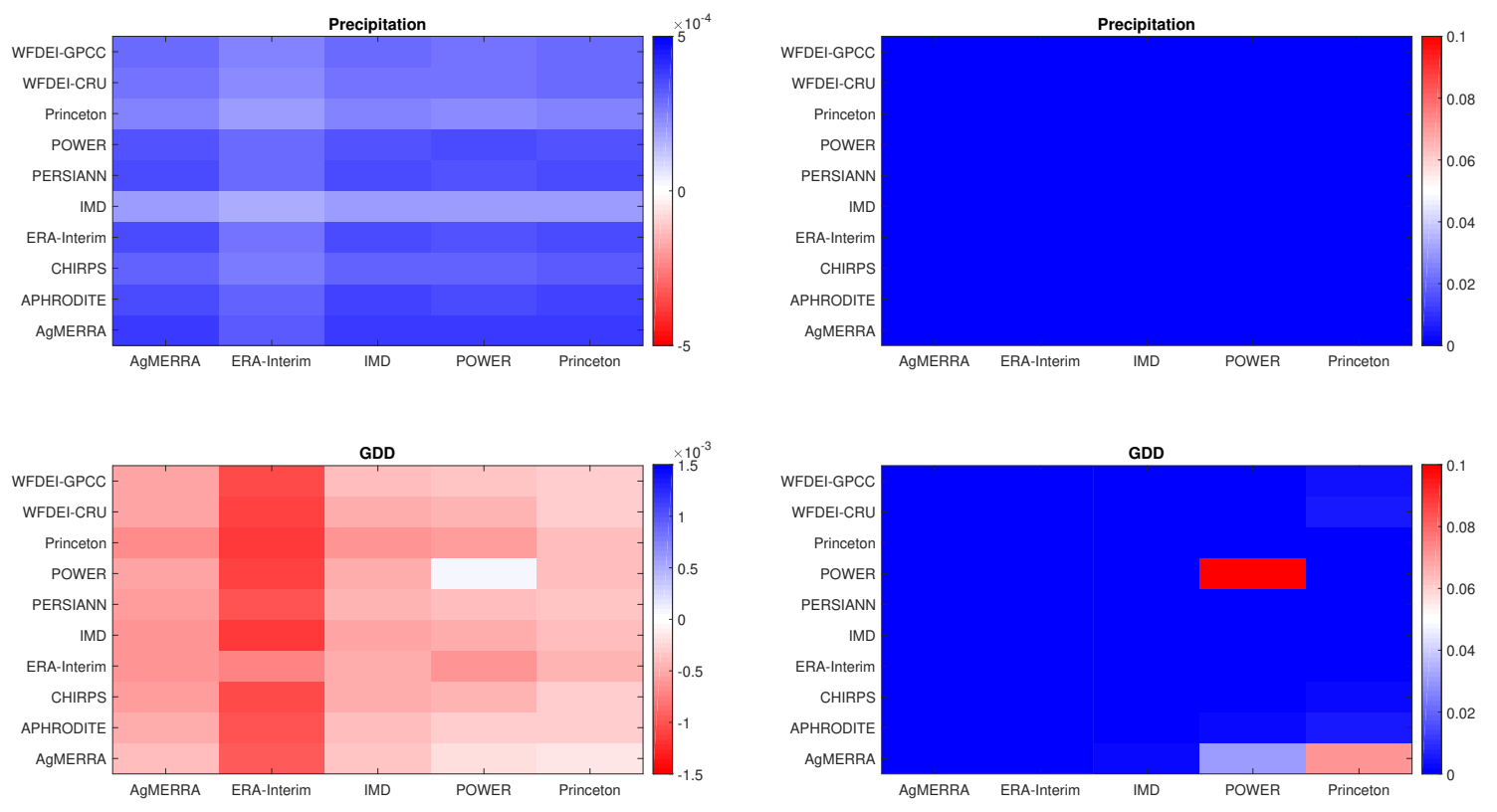

Figure 2. Coefficients (left) and significance values (right) for variables from fixed effects panel regression models for Rice. 

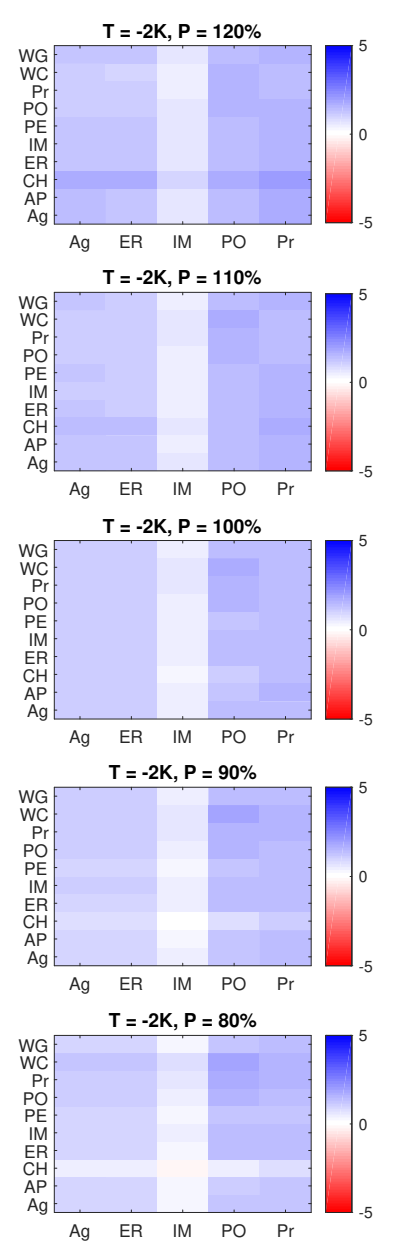
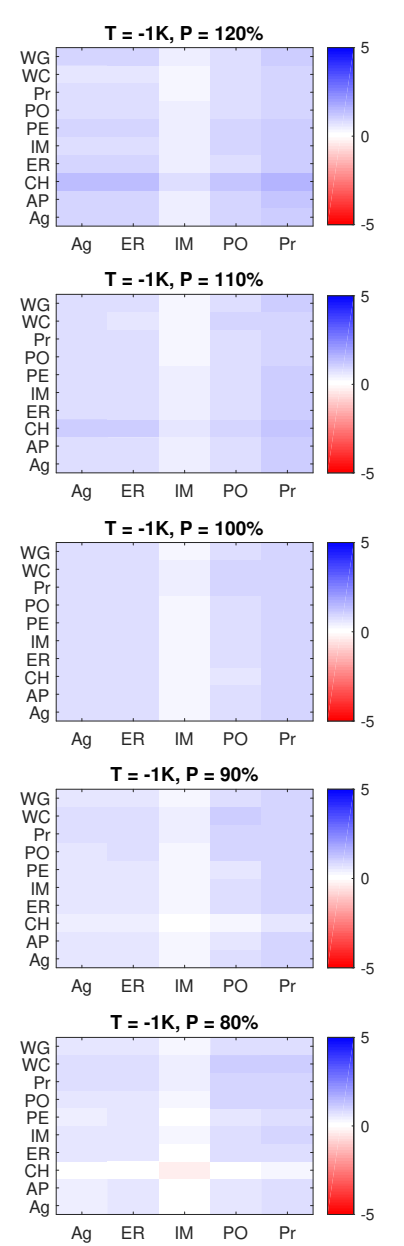
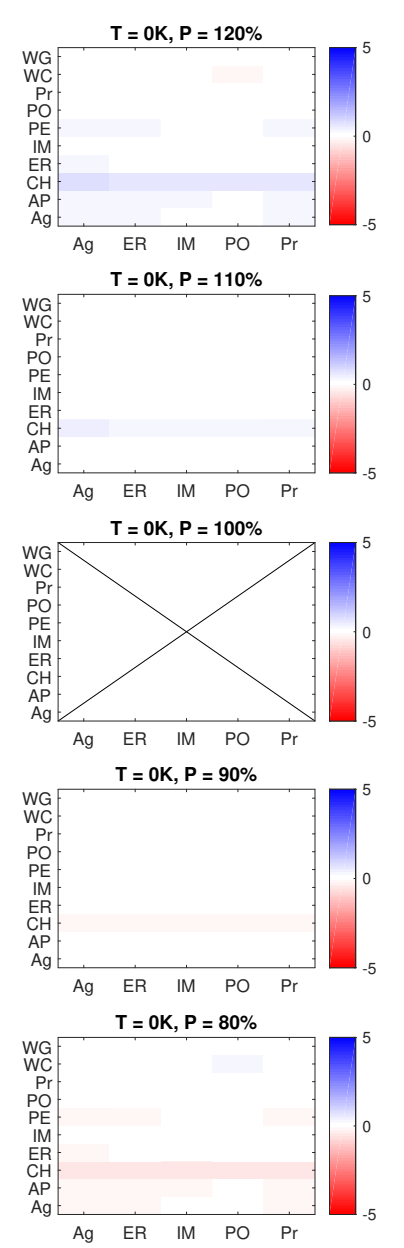
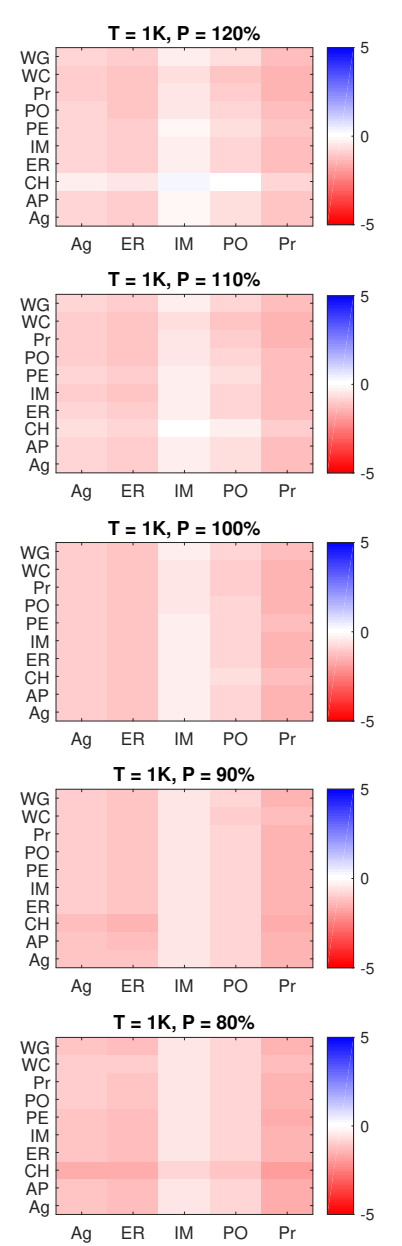
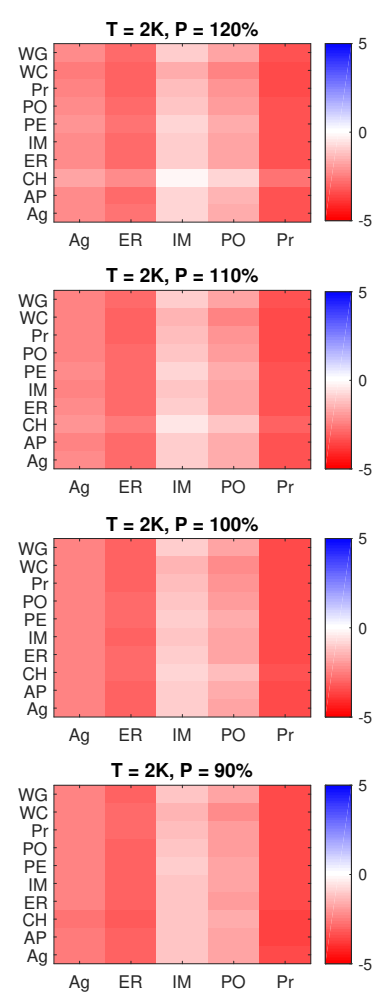

IM $\mathrm{PO}$

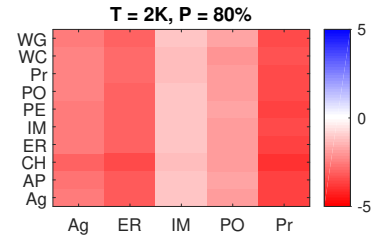

Figure 3. Wheat yield differences (\%) projected as a result of a fixed modification to the input data. The fixed modification is a temperature increase or decrease (columns) and a precipitation increase or decrease (rows). The abbreviations are listed in Table 1. 

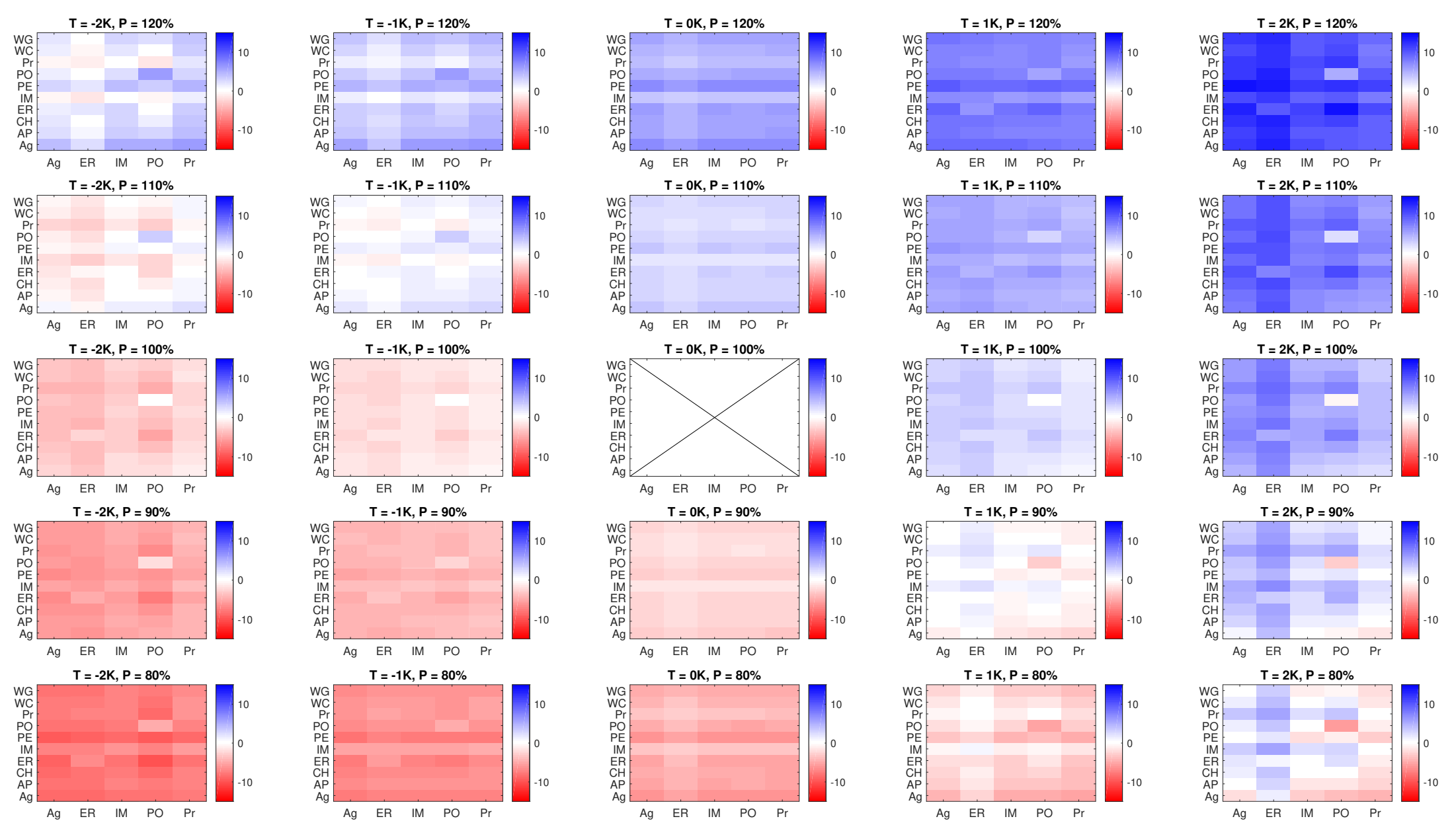

Figure 4. Rice yield differences (\%) projected as a result of a fixed modification to the input data. The fixed modification is a temperature increase or decrease (columns) and a precipitation increase or decrease (rows). The abbreviations are listed in Table 1. 

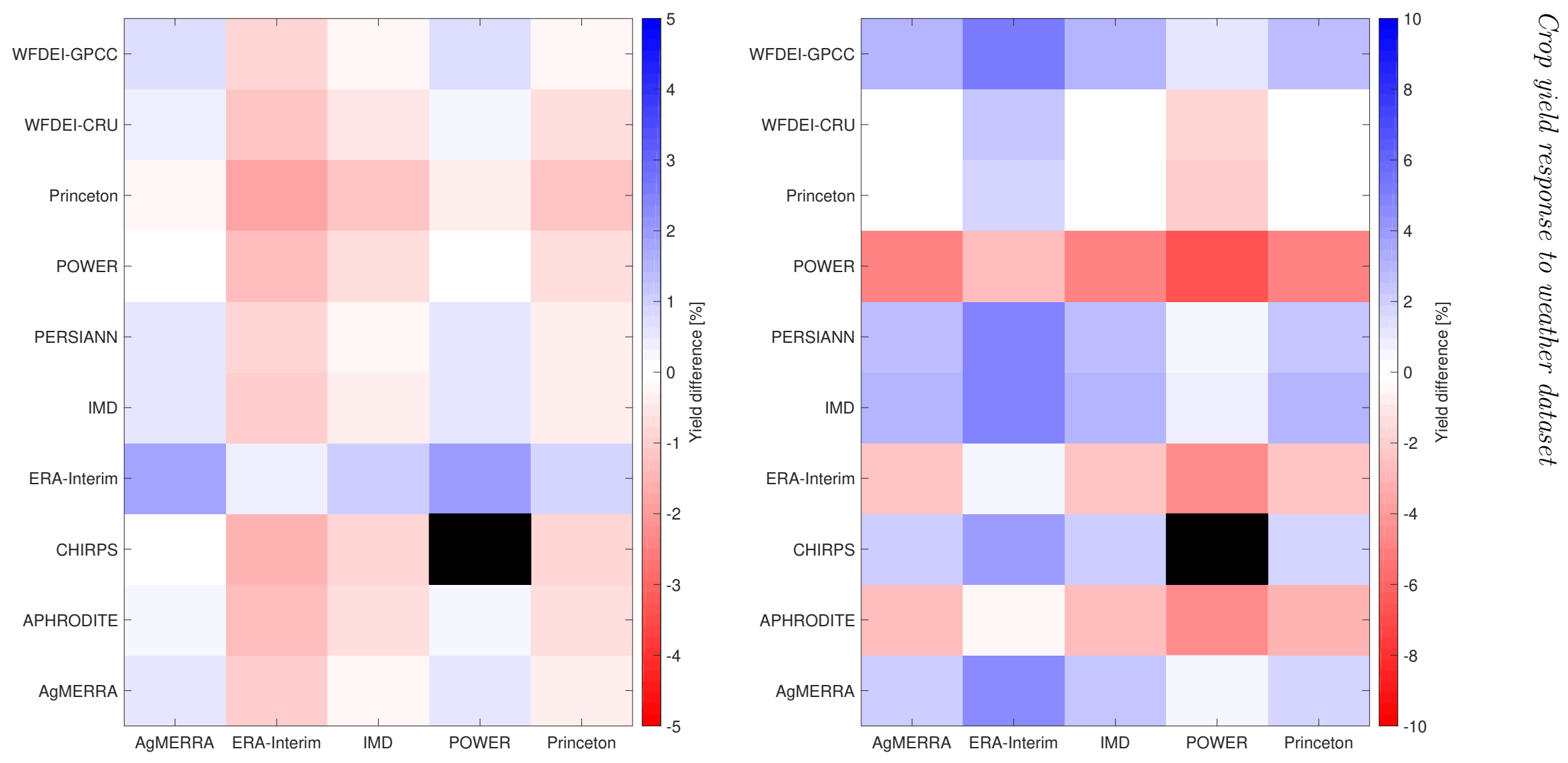

Figure 5. Yield differences (\%) for wheat (left) and rice (right) for the model based on POWER GDDs and EDDs and CHIRPS precipitation when applied to other dataset combinations. 


\section{References}

Aadhar, S. and Mishra, V. (2017). High-resolution near real-time drought monitoring in south asia, Scientific Data 4: 170145.

Ashouri, H., Hsu, K.-L., Sorooshian, S., Braithwaite, D. K., Knapp, K. R., Cecil, L. D., Nelson, B. R. and Prat, O. P. (2015). Persiann-cdr: Daily precipitation climate data record from multisatellite observations for hydrological and climate studies, Bulletin of the American Meteorological Society 96(1): 69-83.

Asseng, S., Cammarano, D., Basso, B., Chung, U., Alderman, P. D., Sonder, K., Reynolds, M. and Lobell, D. B. (2017). Hot spots of wheat yield decline with rising temperatures, Global Change Biology 23(6): 2464-2472.

Auffhammer, M., Ramanathan, V. and Vincent, J. R. (2012). Climate change, the monsoon, and rice yield in india, Climatic Change 111(2): 411-424.

Barnett, B. J. and Mahul, O. (2007). Weather Index Insurance for Agriculture and Rural Areas in Lower-Income Countries, American Journal of Agricultural Economics 89(5): 1241-1247.

Beck, H. E., Vergopolan, N., Pan, M., Levizzani, V., van Dijk, A. I., Weedon, G. P., Brocca, L., Pappenberger, F., Huffman, G. J. and Wood, E. F. (2017). Globalscale evaluation of 22 precipitation datasets using gauge observations and hydrological modeling, Hydrology and Earth System Sciences 21(12): 6201-6217.

Behnke, R., Vavrus, S., Allstadt, A., Albright, T., Thogmartin, W. E. and Radeloff, V. C. (2016). Evaluation of downscaled, gridded climate data for the conterminous united states, Ecological applications 26(5): 1338-1351.

Biemans, H., Siderius, C., Mishra, A. and Ahmad, B. (2016). Crop-specific seasonal estimates of irrigation-water demand in south asia, Hydrology and Earth System Sciences 20(5): 1971-1982.

Cai, R., Cai, R., Yu, D. and Oppenheimer, M. (2014). Estimating the spatially varying responses of corn yields to weather variations using geographically weighted panel regression, Journal of agricultural and resource economics v. 39(no. 2): pp. 230-2522014 v.39 no. 2.

Ceglar, A., Toreti, A., Balsamo, G. and Kobayashi, S. (2017). Precipitation over monsoon asia: A comparison of reanalyses and observations, Journal of Climate 30(2): 465-476.

Clarke, D. J., Mahul, O., Rao, K. N. and Verma, N. (2012). Weather based crop insurance in India, Policy Research Working Paper 5985, The World Bank, Washington, D.C., USA.

Dalhaus, T., Musshoff, O. and Finger, R. (2018). Phenology information contributes to reduce temporal basis risk in agricultural weather index insurance, Scientific reports 8(1): 46.

Daron, J. D. and Stainforth, D. A. (2014). Assessing pricing assumptions for weather index insurance in a changing climate, Climate Risk Management 1: 76-91. 
Datta, K. and Jong, C. (2002). Adverse effect of waterlogging and soil salinity on crop and land productivity in northwest region of haryana, india, Agricultural Water Management 57(3): 223 - 238 .

Dee, D. P., Uppala, S. M., Simmons, A. J., Berrisford, P., Poli, P., Kobayashi, S., Andrae, U., Balmaseda, M. A., Balsamo, G., Bauer, P., Bechtold, P., Beljaars, A. C. M., van de Berg, L., Bidlot, J., Bormann, N., Delsol, C., Dragani, R., Fuentes, M., Geer, A. J., Haimberger, L., Healy, S. B., Hersbach, H., Hólm, E. V., Isaksen, L., Kållberg, P., Köhler, M., Matricardi, M., McNally, A. P., Monge-Sanz, B. M., Morcrette, J.-J., Park, B.-K., Peubey, C., de Rosnay, P., Tavolato, C., Thépaut, J.-N. and Vitart, F. (2011). The era-interim reanalysis: configuration and performance of the data assimilation system, Quarterly Journal of the Royal Meteorological Society 137(656): 553-597.

DeFries, R., Mondal, P., Singh, D., Agrawal, I., Fanzo, J., Remans, R. and Wood, S. (2016). Synergies and trade-offs for sustainable agriculture: Nutritional yields and climate-resilience for cereal crops in central india, Global Food Security 11: 44 - 53. 2nd International Global Food Security Conference.

Duncan, J. M. A., Dash, J. and Atkinson, P. M. (2015). Elucidating the impact of temperature variability and extremes on cereal croplands through remote sensing, Global Change Biology 21(4): 1541-1551.

Duncan, J., Saikia, S., Gupta, N. and Biggs, E. (2016). Observing climate impacts on tea yield in assam, india, Applied Geography 77: $64-71$.

Fishman, R. (2016). More uneven distributions overturn benefits of higher precipitation for crop yields, Environmental Research Letters 11(2): 024004.

Fontes, F. P., Gorst, A. and Palmer, C. (2017). Does choice of drought index influence estimates of drought-induced cereal losses in India?, GRI Working Papers 274 , Grantham Research Institute on Climate Change and the Environment.

Foster, T., Brozović, N., Butler, A., Neale, C., Raes, D., Steduto, P., Fereres, E. and Hsiao, T. C. (2017). Aquacrop-os: An open source version of fao's crop water productivity model, Agricultural water management 181: 18-22.

Funk, C., Peterson, P., Landsfeld, M., Pedreros, D., Verdin, J., Shukla, S., Husak, G., Rowland, J., Harrison, L., Hoell, A. and Michaelsen, J. (2015). The climate hazards infrared precipitation with stations-a new environmental record for monitoring extremes, Scientific Data 2: 150066.

Gilmont, M., Hall, J., Grey, D., Dadson, S., Abele, S. and Simpson, M. (2018). Analysis of the relationship between rainfall and economic growth in indian states, Global Environmental Change 49: 56 - 72.

Harris, I., Jones, P., Osborn, T. and Lister, D. (2013). Updated high-resolution grids of monthly climatic observations - the cru ts3.10 dataset, International Journal of Climatology 34(3): 623-642. 
Heft-Neal, S., Lobell, D. B. and Burke, M. (2017). Using remotely sensed temperature to estimate climate response functions, Environmental Research Letters 12(1): 014013.

Holzworth, D. P., Huth, N. I., deVoil, P. G., Zurcher, E. J., Herrmann, N. I., McLean, G., Chenu, K., van Oosterom, E. J., Snow, V., Murphy, C., Moore, A. D., Brown, H., Whish, J. P., Verrall, S., Fainges, J., Bell, L. W., Peake, A. S., Poulton, P. L., Hochman, Z., Thorburn, P. J., Gaydon, D. S., Dalgliesh, N. P., Rodriguez, D., Cox, H., Chapman, S., Doherty, A., Teixeira, E., Sharp, J., Cichota, R., Vogeler, I., Li, F. Y., Wang, E., Hammer, G. L., Robertson, M. J., Dimes, J. P., Whitbread, A. M., Hunt, J., van Rees, H., McClelland, T., Carberry, P. S., Hargreaves, J. N., MacLeod, N., McDonald, C., Harsdorf, J., Wedgwood, S. and Keating, B. A. (2014). Apsim evolution towards a new generation of agricultural systems simulation, Environmental Modelling \& Software 62: 327 - 350 .

Hufkens, K., Melaas, E. K., Mann, M. L., Foster, T., Ceballos, F., Robles, M. and Kramer, B. (2019). Monitoring crop phenology using a smartphone based near-surface remote sensing approach, Agricultural and Forest Meteorology 265: 327 - 337.

Jain, M., Singh, B., Srivastava, A. A. K., Malik, R. K., McDonald, A. J. and Lobell, D. B. (2017). Using satellite data to identify the causes of and potential solutions for yield gaps in india's wheat belt, Environmental Research Letters 12(9): 094011.

Lobell, D. B. and Burke, M. B. (2010). On the use of statistical models to predict crop yield responses to climate change, Agricultural and Forest Meteorology 150(11): 1443 -1452 .

Lobell, D. B., Sibley, A. and Ivan Ortiz-Monasterio, J. (2012). Extreme heat effects on wheat senescence in india, Nature Climate Change 2: 186.

Mathison, C., Wiltshire, A., Dimri, A., Falloon, P., Jacob, D., Kumar, P., Moors, E., Ridley, J., Siderius, C., Stoffel, M. and Yasunari, T. (2013). Regional projections of north indian climate for adaptation studies, Science of The Total Environment 468-469: S4 - S17. Changing water resources availability in Northern India with respect to Himalayan glacier retreat and changing monsoon patterns: consequences and adaptation.

Menne, M. J., Durre, I., Vose, R. S., Gleason, B. E. and Houston, T. G. (2012). An overview of the global historical climatology network-daily database, Journal of atmospheric and oceanic technology 29(7): 897-910.

Mishra, V., Shah, R. and Thrasher, B. (2014). Soil moisture droughts under the retrospective and projected climate in india, Journal of Hydrometeorology 15(6): 2267-2292.

Mondal, S., Singh, R., Mason, E., Huerta-Espino, J., Autrique, E. and Joshi, A. (2016). Grain yield, adaptation and progress in breeding for early-maturing and heat-tolerant wheat lines in south asia, Field Crops Research 192: 78 - 85.

Mourtzinis, S., Edreira, J. I. R., Conley, S. P. and Grassini, P. (2017). From grid to field: Assessing quality of gridded weather data for agricultural applications, European Journal of Agronomy 82: 163-172. 
Pai, D., Sridhar, L., Rajeevan, M., Sreejith, O., Satbhai, N. and Mukhopadhyay, B. (2014). Development of a new high spatial resolution $(0.25 \times 0.25)$ long period $(1901-$ 2010) daily gridded rainfall data set over india and its comparison with existing data sets over the region, Mausam 65(1): 1-18.

Parkes, B., Defrance, D., Sultan, B., Ciais, P. and Wang, X. (2018). Projected changes in crop yield mean and variability over west africa in a world $1.5 \mathrm{k}$ warmer than the pre-industrial era, Earth System Dynamics 9(1): 119-134.

Parkes, B., Sultan, B., Ciais, P. and Wang, X. (2017). Modelling fertiliser significance in three major crops, European Journal of Agronomy 90: 1 - 11.

Porwollik, V., Müller, C., Elliott, J., Chryssanthacopoulos, J., Iizumi, T., Ray, D. K., Ruane, A. C., Arneth, A., Balkovič, J., Ciais, P., Deryng, D., Folberth, C., Izaurralde, R. C., Jones, C. D., Khabarov, N., Lawrence, P. J., Liu, W., Pugh, T. A., Reddy, A., Sakurai, G., Schmid, E., Wang, X., de Wit, A. and Wu, X. (2017). Spatial and temporal uncertainty of crop yield aggregations, European Journal of Agronomy 88: $10-21$. Uncertainty in crop model predictions.

Rajeevan, M. and Bhate, J. (2009). A high resolution daily gridded rainfall dataset (1971-2005) for mesoscale meteorological studies, Current Science pp. 558-562.

Roberts, M. J., Braun, N. O., Sinclair, T. R., Lobell, D. B. and Schlenker, W. (2017). Comparing and combining process-based crop models and statistical models with some implications for climate change, Environmental Research Letters 12(9): 095010.

Romaguera, M., Hoekstra, A. Y., Su, Z., Krol, M. S. and Salama, M. S. (2010). Potential of using remote sensing techniques for global assessment of water footprint of crops, Remote Sensing 2(4): 1177-1196.

Rosenzweig, C., Elliott, J., Deryng, D., Ruane, A. C., Müller, C., Arneth, A., Boote, K. J., Folberth, C., Glotter, M., Khabarov, N. et al. (2014). Assessing agricultural risks of climate change in the 21st century in a global gridded crop model intercomparison, Proceedings of the National Academy of Sciences 111(9): 3268-3273.

Ruane, A. C., Goldberg, R. and Chryssanthacopoulos, J. (2015). Climate forcing datasets for agricultural modeling: Merged products for gap-filling and historical climate series estimation, Agricultural and Forest Meteorology 200: 233 - 248.

Schlenker, W. and Roberts, M. J. (2009). Nonlinear temperature effects indicate severe damages to us crop yields under climate change, Proceedings of the National Academy of sciences 106(37): 15594-15598.

Schneider, U., Becker, A., Finger, P., Meyer-Christoffer, A., Ziese, M. and Rudolf, B. (2014). Gpcc's new land surface precipitation climatology based on quality-controlled in situ data and its role in quantifying the global water cycle, Theoretical and Applied Climatology 115(1): 15-40.

Sheffield, J., Goteti, G. and Wood, E. F. (2006). Development of a 50-year highresolution global dataset of meteorological forcings for land surface modeling, Journal of Climate 19(13): 3088-3111. 
Stackhouse, P. W., Zhang, T., Westberg, D., Barnett, A. J., Bristow, T., Macpherson, B. and Hoell, J. M. (2018). Power release 8 (with gis applications) methodology (data parameters, sources, \& validation), Technical report, NASA Langley Research Centre.

Tack, J., Barkley, A. and Nalley, L. L. (2015). Effect of warming temperatures on us wheat yields, Proceedings of the National Academy of Sciences 112(22): 6931-6936.

Tebaldi, C. and Knutti, R. (2007). The use of the multi-model ensemble in probabilistic climate projections, Philosophical transactions of the royal society A: mathematical, physical and engineering sciences 365(1857): 2053-2075.

van Oort, P., Zhang, T., de Vries, M., Heinemann, A. and Meinke, H. (2011). Correlation between temperature and phenology prediction error in rice (oryza sativa 1.), Agricultural and Forest Meteorology 151(12): 1545 - 1555.

Van Wart, J., Grassini, P. and Cassman, K. G. (2013). Impact of derived global weather data on simulated crop yields, Global change biology 19(12): 3822-3834.

Van Wart, J., Grassini, P., Yang, H., Claessens, L., Jarvis, A. and Cassman, K. G. (2015). Creating long-term weather data from thin air for crop simulation modeling, Agricultural and Forest Meteorology 209: 49-58.

Weedon, G. P., Balsamo, G., Bellouin, N., Gomes, S., Best, M. J. and Viterbo, P. (2014). The wfdei meteorological forcing data set: Watch forcing data methodology applied to era-interim reanalysis data, Water Resources Research 50(9): 7505-7514.

Yatagai, A., Kamiguchi, K., Arakawa, O., Hamada, A., Yasutomi, N. and Kitoh, A. (2012). Aphrodite: Constructing a long-term daily gridded precipitation dataset for asia based on a dense network of rain gauges, Bulletin of the American Meteorological Society 93(9): 1401-1415. 


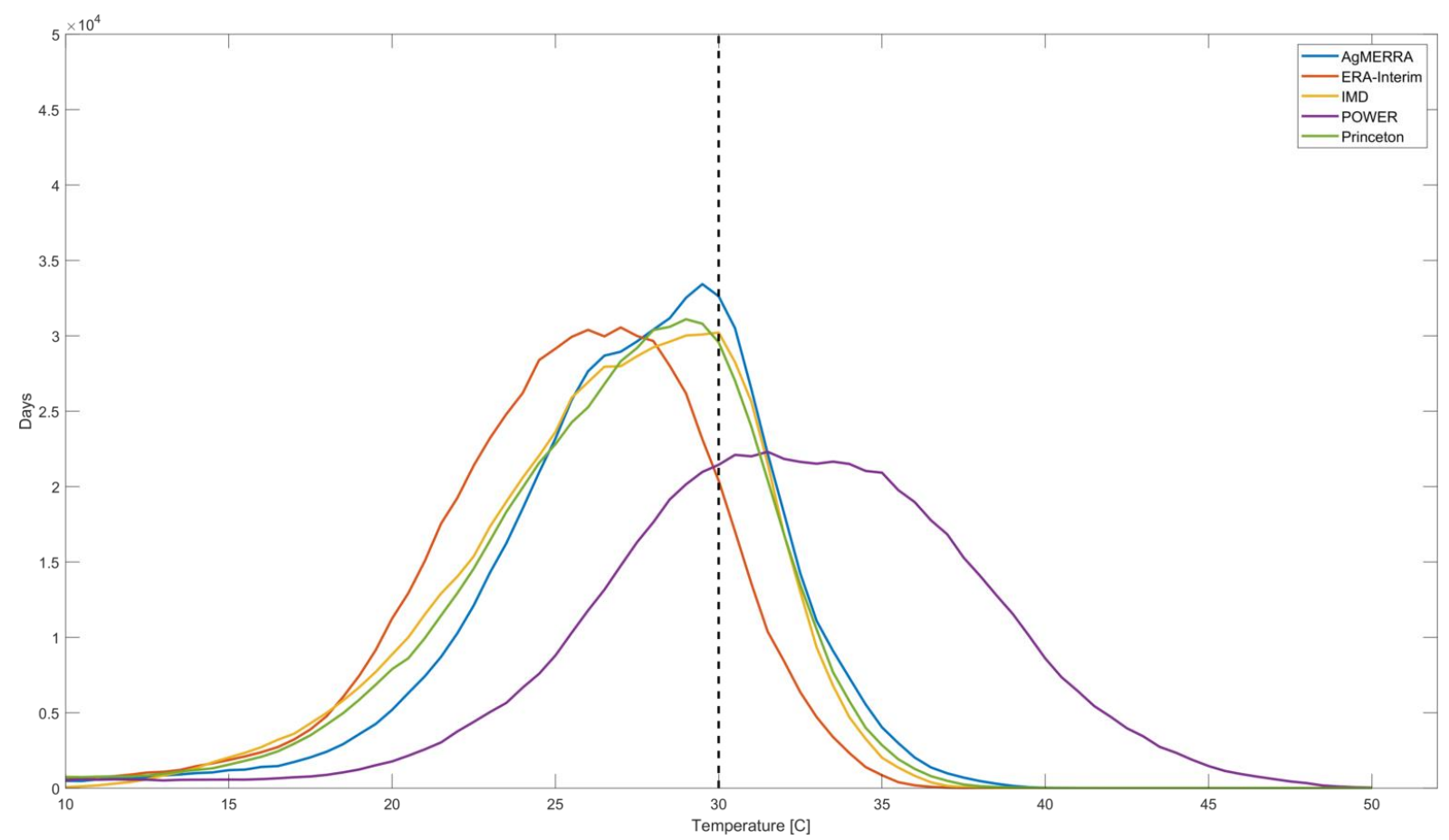

SI Figure 1: Pdf of maximum daily district mean temperature for five datasets for wheat growing season in India. The results of note here are the difference between POWER and ERA-Interim and the other three datasets. ERA-Interim peaks at a lower temperature than the other datasets and therefore has a smaller number of days above the $30 \mathrm{C}$ limit for extreme degree-days. The POWER results show a much larger spread and a lower peak than the other datasets. The POWER dataset provides a higher number of extreme degree-days; this causes the models to reduce sensitivity to extreme temperatures.

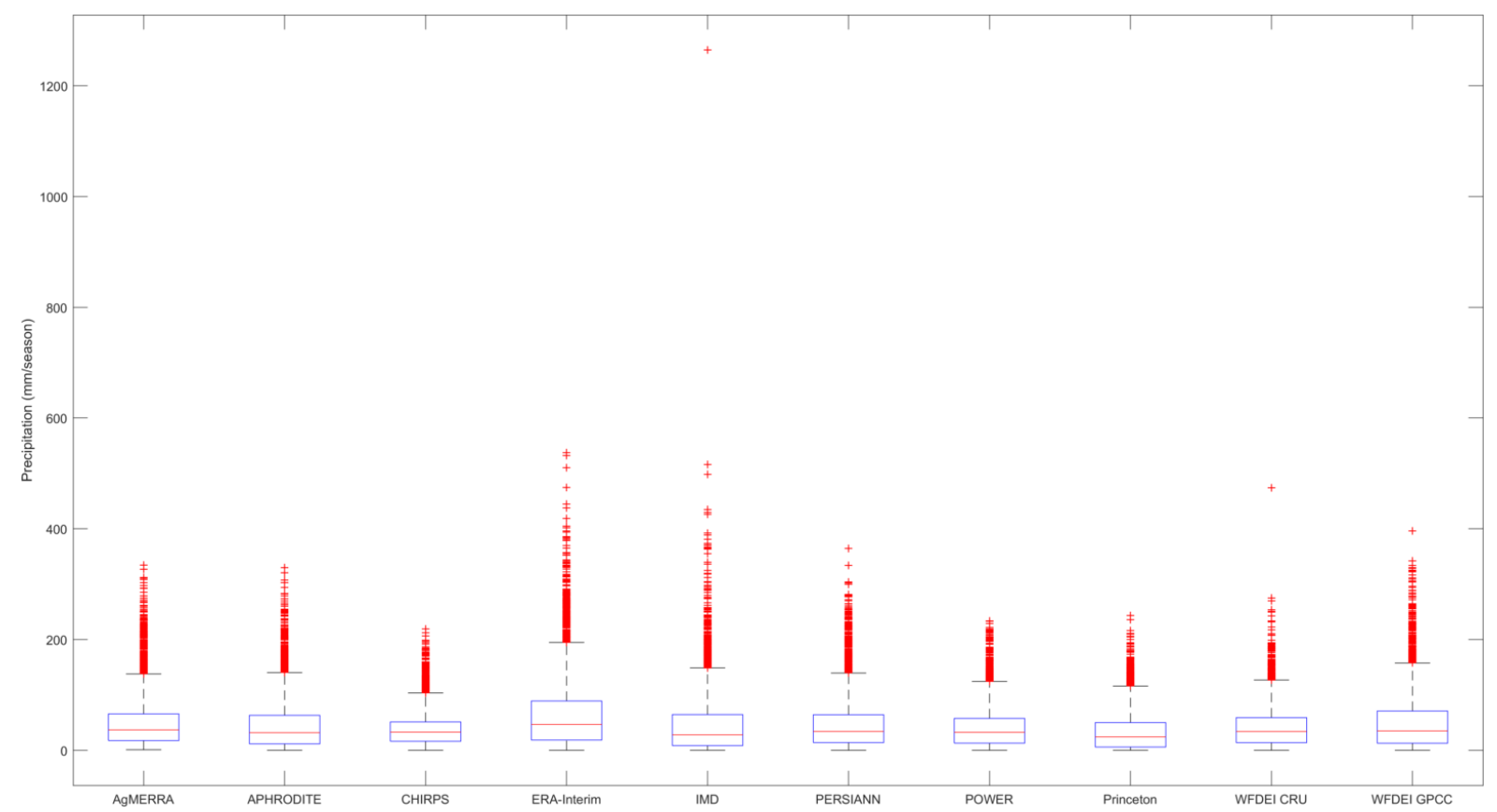

SI Figure 2: Boxplot of the seasonal total precipitation for the wheat-growing season for ten reference datasets. The median value is the red bar with the $25^{\text {th }}$ and $75^{\text {th }}$ percentile values with the whiskers showing the values not deemed outliers. The red + marks show outlier values. 

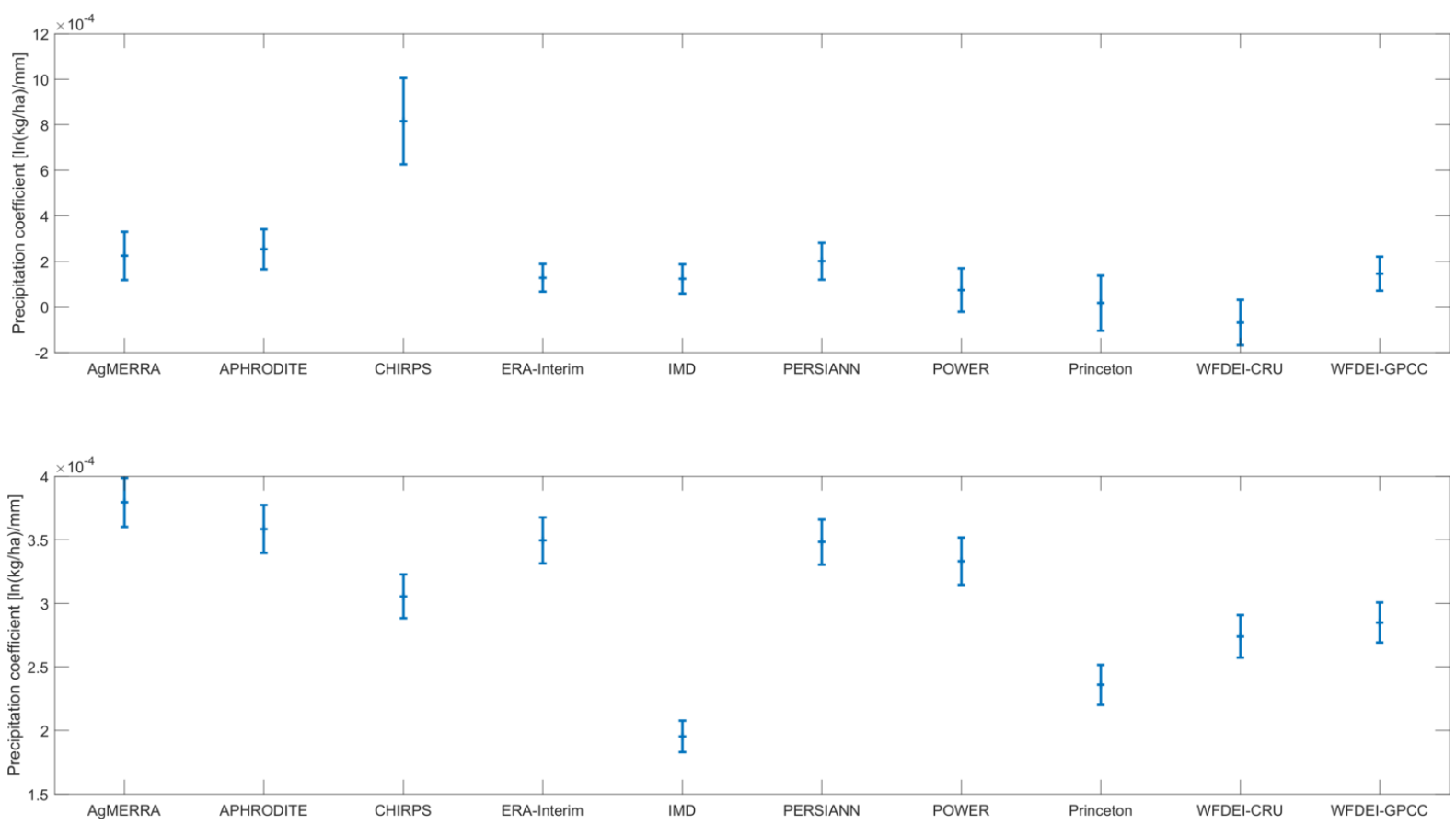

SI Figure 3: Coefficients of precipitation term for Wheat (top) and Rice (bottom) where the error bar shows the standard deviation in values across the five temperature datasets. The CHIRPS dataset has a larger coefficient than the other datasets in the wheat models.
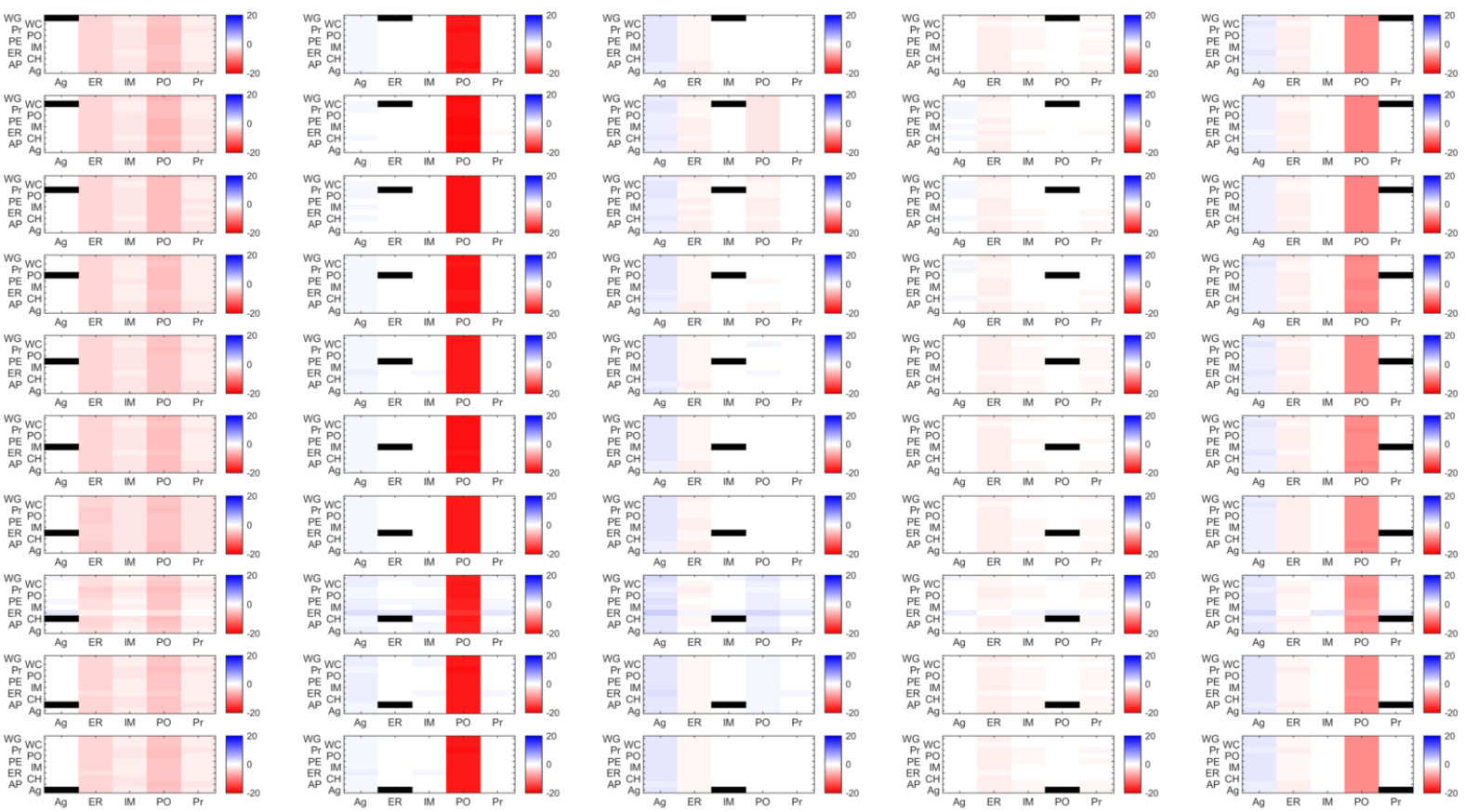

SI Figure 4: Wheat yield differences [\%] projected as a result of using different reference datasets where the black box indicates the model. The temperature datasets are constant in each column and the precipitation datasets are constant in each row. See Table 1 for definitions of the abbreviations. 

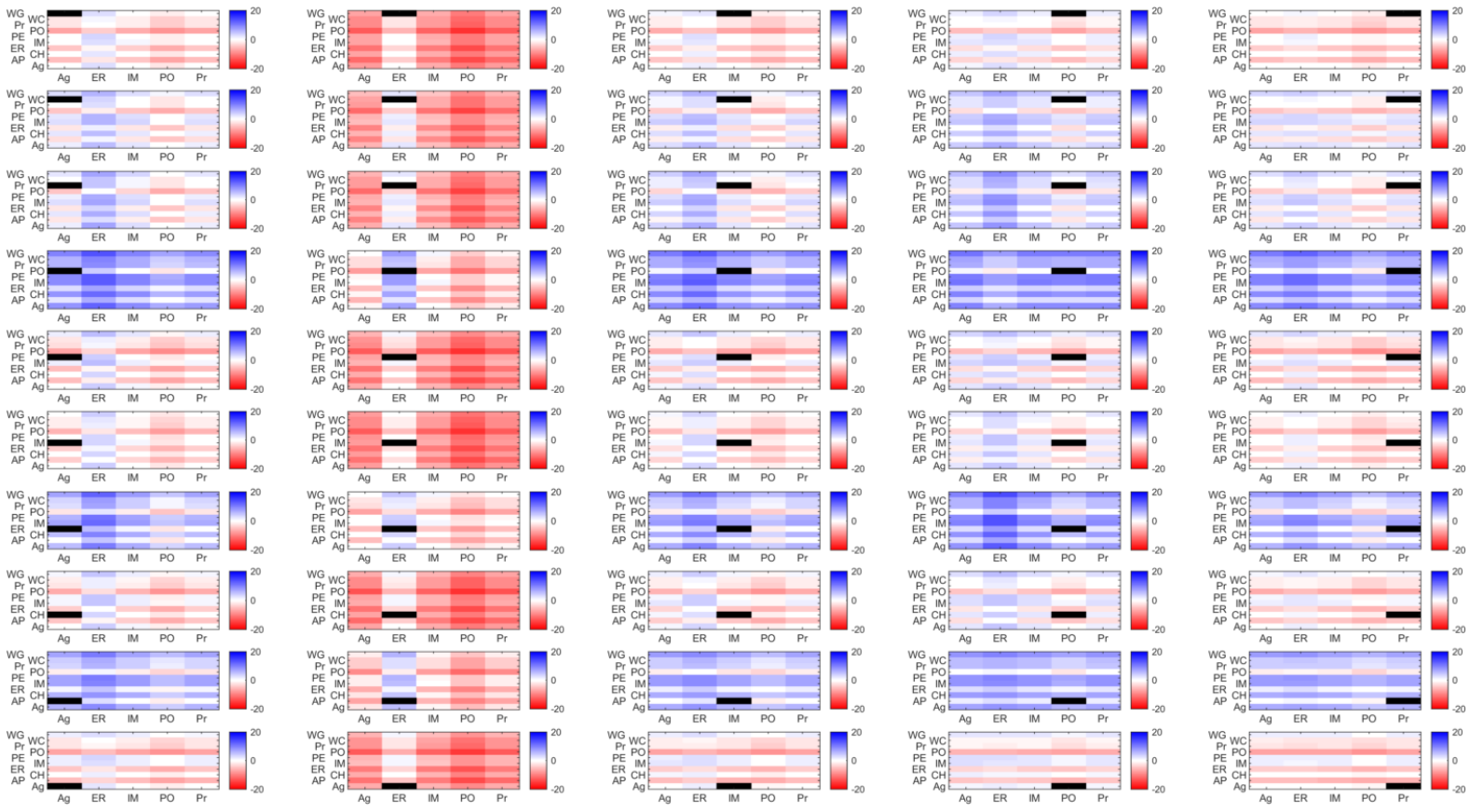

SI Figure 5: Rice yield differences [\%] projected as a result of using different reference datasets where the black box indicates the model. The temperature datasets are constant in each column and the precipitation datasets are constant in each row. See Table 1 for definitions of the abbreviations.
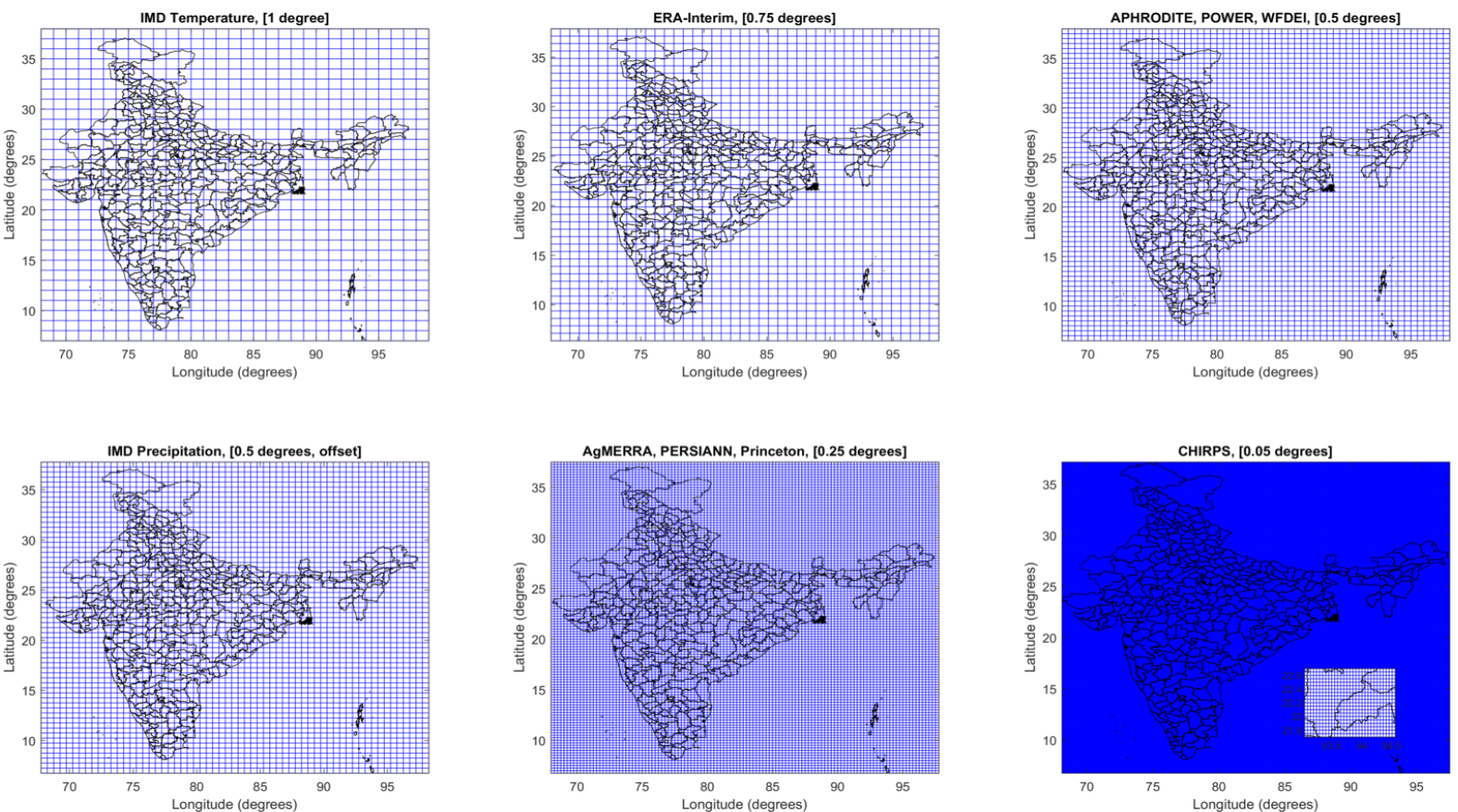

SI Figure 6: Grid cell locations for datasets used in this study. The IMD temperature dataset is coarsest followed by ERA-Interim. APHRODITE, POWER, WFDEI-CRU and WFDEI-GPCC are all 0.5degree resolution; the IMD precipitation is also at 0.5 -degree resolution but is offset by 0.25 degrees from the other datasets. AgMERRA, PERSIANN and Princeton all use a 0.25 -degree resolution. Finally, CHIRPS has a 0.05-degree resolution and a high-resolution snapshot showing the region near the North West border of Odisha and West Bengal is shown in the bottom right of the plot. The ICRISAT VDSA (Village Dynamics in South Asia) yield database used district names from 1966, a 1961 Indian district shapefile is used to maintain consistency and does not reflect the current political borders in disputed regions in South Asia. 


\section{ALL IFPRI DISCUSSION PAPERS}

All discussion papers are available here

They can be downloaded free of charge

INTERNATIONAL FOOD POLICY RESEARCH INSTITUTE

www.ifpri.org

\section{IFPRI HEADQUARTERS}

1201 Eye Street, NW

Washington, DC 20005 USA

Tel.: +1-202-862-5600

Fax: +1-202-862-5606

Email: ifpri@cgiar.org

SOUTH ASIA REGIONAL OFFICE

Block C, NASC Complex, DPS Marg

Opposite Todapur, Pusa

New Delhi 110012 India

Phone: +91-11-66166565

Fax: +91-11-66781699

Email: ifpri-newdelhi@cgiar.org

https://southasia.ifpri.info 